\title{
Study of Equivalent Strength and Effects of the Type of Multi-story Steel Braced Frames
}

Takayuki Kinoshita* and Takumi Ito

Department of Architecture, Tokyo University of Science, Japan

\begin{abstract}
In recent years, the terrible earthquake events that are not expected in the design process have occurred in the world. So, it is necessary to estimate the seismic performance accurately. This paper focuses on the energy absorbing efficiency of steel braced frames. Steel brace members in frames show the complicated and unstable behavior because many kinds of buckling and fractures are combined. And evaluation method of restoring force characteristics and capacity have been studied in enormous past researches, however, there are some problems to adopt for seismic design procedure. Also the response characteristics of steel braced frames are affected by the interaction between frames and braces. This paper suggests the analytical method to evaluate the energy absorbing efficiency of steel braced frames as equivalent strength. The equivalent strength is formulated with yield shear coefficient of the frame and slenderness ratio of the brace. Also, to verify the applicability of multi-story steel braced frames response analysis of two types of 5-story steel braced frames ( $X$ bracing, inverted-V bracing) is conducted. As compared with energy absorbing efficiency of the response analysis result, it is confirmed that the equivalent strength can be accuracy of plus or minus 20 percent or so.
\end{abstract}

Keywords: Steel braced frames; Restoring force characteristics; Buckling; Seismic performance; Equivalent strength

\section{Introduction}

Japanese seismic design code [1] prescribes that building structures must keep sufficient seismic performance such as ultimate strength, ductility, energy absorbing capacity under terrible earthquake input. A lot of past researches have investigated buckling resistant capacity, and energy absorbing capacity. Furthermore, evaluation methods on inelastic behavior and buckling strength, post-buckling stable strength and energy absorbing capacity until the braces reaches the ultimate state of braces have been established. According to design guideline of building structures based on energy absorbing capacity [2], which the energy absorbing capacity is important index to evaluate seismic performance of steel braced frames. Steel braces are one of important components of seismic resistant members of steel structures, and they increase rigidity and strength of stories. However, it is commonly recognized that the braces during ultimate state show unstable behavior caused by buckling and crack. Therefore, in past researches, several restoring force and hysteresis characteristic models of steel compression members $[3,4]$ have been proposed, however, simple methods to evaluate seismic performance are required in general seismic design. In consequence, it is necessary to quantitatively evaluate seismic performance. In recent researches in the world, the behavior of braces and steel constructions have been treated, e.g. model for cyclic inelastic buckling of steel braces is presented [5] a useful method to predict the behavior of steel braces is proposed [6], and the robustness assessment methods of steel framed buildings under catastrophic events are treated [7]. This paper suggests the method to evaluate energy absorbing efficiency of steel braces as equivalent strength [8] based on energy absorption of steel braces after seismic response. Moreover, to clarify the applicability of equivalent strength, response analysis of two types of five-story three-bay steel braced frames have been conducted and compares evaluation values of suggested equivalent strength with analytical results.

\section{Energy Absorbing Efficiency of Steel Braced Frames}

The inelastic behavior of steel structures under earthquake is influenced by vibration characteristics of structures and phase characteristic of the input earthquake motion. Regarding braced frames, this behavior is generated by buckling of braces. In this study, it is assumed that the displacement history of the braces is almost same with moment resisting frame. The accuracy of random vibration is lost; however, this supposition takes account of the inelastic response characteristics of braces generally. The analytical procedure to evaluate the energy absorbing efficiency of braces is as follows:

1) Response displacement history is estimated from the result of response analysis of moment resisting frames (which braces are not installed).

2) Hysteresis loop of a pair of braces is estimated from the above response displacement history.

3) This hysteresis loop of a pair of braces is translated into equivalent perfect elasto-plasticity. Energy absorbing efficiency of a pair of braces is expressed as the strength of elastic perfectly plastic (herein after referred, this is called "equivalent strength").

\section{Response displacement history of moment resisting frames}

Regarding vibration systems which has spindle- shaped restoring force characteristics such as moment resisting frames, seismic response displacement corresponded to the coefficient of structural characteristic (Ds, which is defined as standard strength of frames on Japanese seismic design code) [1] is estimated. Figure 1 shows an analytical model. The storing force model of moment resisting frames is Skeleton Shift Model [9]. Figure 2 shows skeleton curve and hysteresis rule of Skeleton Shift Model. Table 1 shows analytical variables. Herein, total seismic input energy of RDs030 is a standard model, and seismic input energy of the other models is adjusted to

*Corresponding author: Takayuki Kinoshita, Department of Architecture, Tokyo University of Science, Japan, Tel: +813-3260-4271; E-mail: 4116619@ed.tus.ac.jp

Received July 06, 2016; Accepted July 28, 2016; Published July 30, 2016

Citation: Kinoshita T, Ito T (2016) Study of Equivalent Strength and Effects of the Type of Multi-story Steel Braced Frames. J Civil Environ Eng S3:005. doi:10.4172/2165-784X.S3-005

Copyright: (c) 2016 Kinoshita T, et al. This is an open-access article distributed under the terms of the Creative Commons Attribution License, which permits unrestricted use, distribution, and reproduction in any medium, provided the original author and source are credited 


\section{Moment Resisting Frame (2.1)}

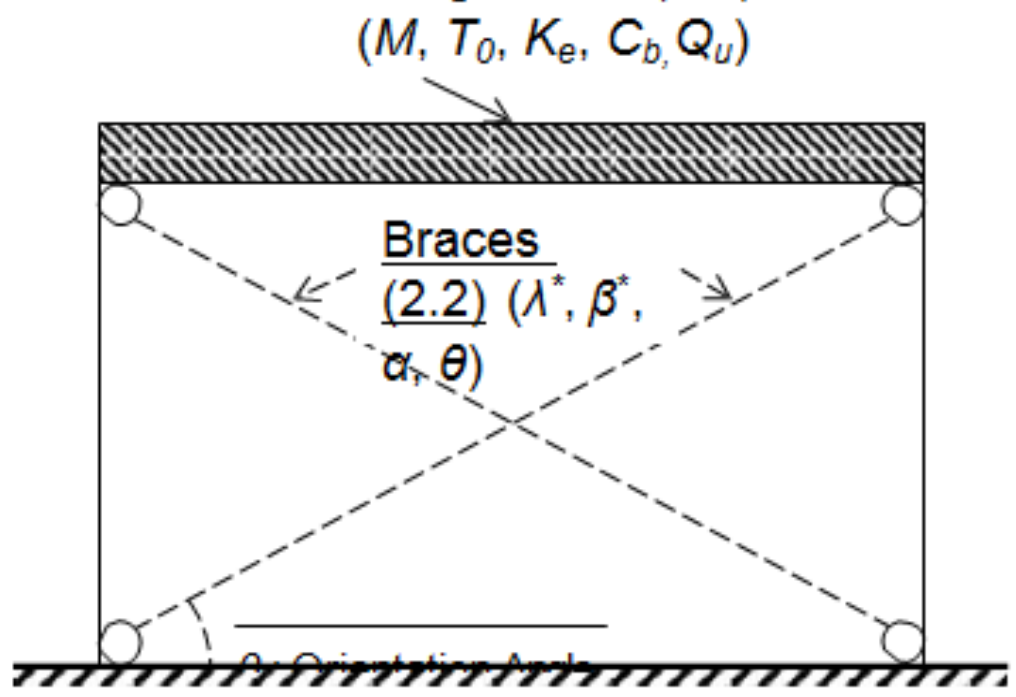

Figure 1: Analytical model.
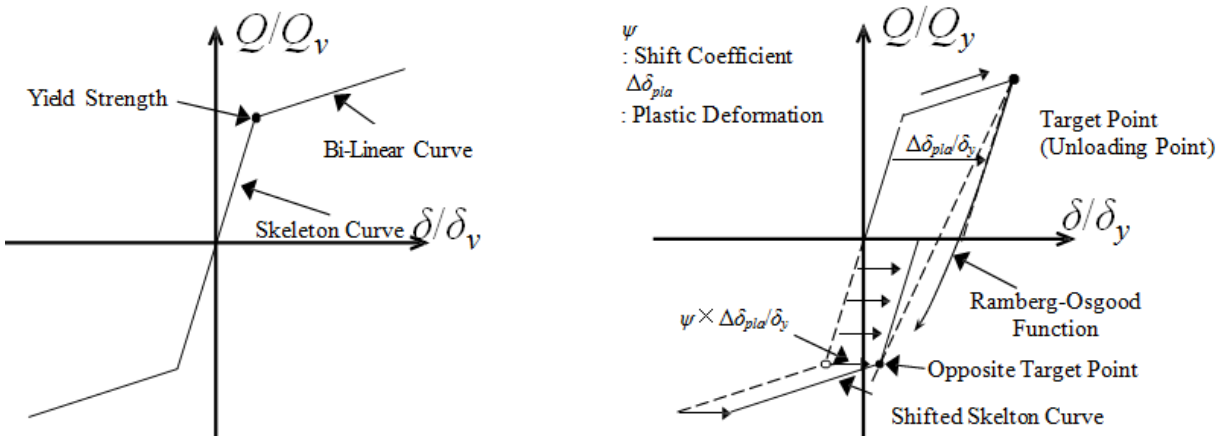

Figure 2: Skeleton curve and hysteresis rule of the skeleton shift model [9].

\begin{tabular}{|c|c|c|c|c|c|}
\hline Analytical model & Mass $M$ (ton) & Natural period $T 0$ (sec) & Elastic rigidity $K e(\mathrm{kN} / \mathrm{mm})$ & Yield base shear coefficient $C_{b}(-)$ & Ultimate lateral strength $Q_{u}(\mathrm{kN})$ \\
\hline $\mathrm{RDs} 025$ & \multirow{7}{*}{2000} & \multirow{7}{*}{1.00} & \multirow{7}{*}{ 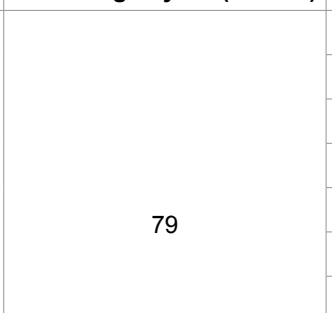 } & 0.25 & 4900 \\
\hline $\mathrm{RDs} 030$ & & & & 0.30 & 5880 \\
\hline RDs035 & & & & 0.35 & 6860 \\
\hline $\mathrm{RDs} 040$ & & & & 0.40 & 7840 \\
\hline RDs045 & & & & 0.45 & 8820 \\
\hline RDs050 & & & & 0.50 & 9800 \\
\hline RDs055 & & & & 0.55 & 10780 \\
\hline
\end{tabular}

Table 1: Analytical variables related to moment resisting frames.

the same as RDs030. In addition, input motions are El Centro NS, Hachinohe EW, and Fukiai NS.

\section{Hysteresis loop of steel braces}

Restoring force characteristics of steel braces is as shown in Figure 3 [10]. This model is modified based on the "Wakabayashi model" [3]. In addition, the wide range of analytical variables is allowable, which is formulated by reference of enormous past test data. Herein, the response displacement history of moment resisting frames in the preceding paragraph is translated into that of a pair of braces. Hysteresis loop of a pair of braces is estimated with simulated from the response displacement history. If a pair of braces is connected with the moment resisting frames $\left(C_{b}=0.25\right)$, for example, the displacement history of RDs025 is translated into the displacement history of the pair of braces. Table 2 shows analytical variables related to braces. Analytical variables are as follows: non-dimensional slenderness ratio $\lambda^{\star}$, non-dimensional width-thickness ratio $\beta^{\star}$, yield deformation ratio $\alpha$ of the yield deformation of braces to the yield deformation of moment resisting frames, and orientation angle of braces $\theta$. In addition, local buckling occurs in the flange part first in regard to $\mathrm{H}$ section, therefore, the width thickness ratio of flange part is used (Figure 4). Where $\lambda^{\star}$ and $\beta^{*}$ are given as following: 


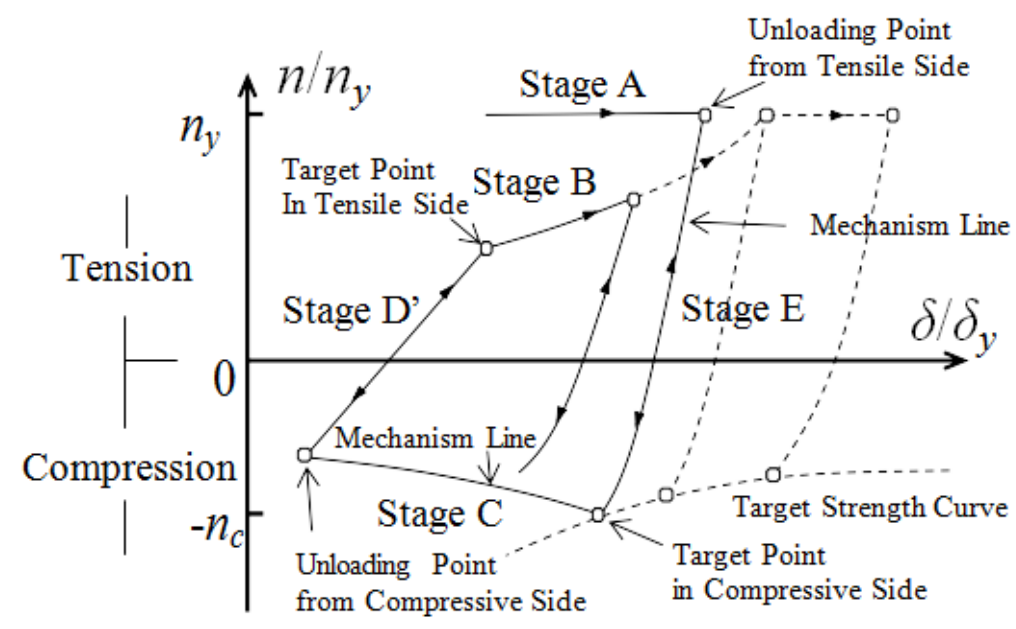

Figure 3: Restoring force characteristics of braces [10]. (Stage A: Full plastic state in tension. Stage B: The section near the center of the member is in the yield state by a tensile force and a moment. The member is a stage where it has been extended from the state where it was crooked. Stage C: The section near the center of the member is in the yield state by a compressive force and a moment. The member is a stage where it is crooked rapidly. Stage D: Elastic unloading state from the compressive side. Stage E: Elastic unloading state from the tensile side).

\begin{tabular}{|c|c|c|c|}
\hline Section & $\boldsymbol{\Lambda}^{*}$ & $\mathbf{B}^{\boldsymbol{*}}$ & $\boldsymbol{\boldsymbol { \alpha }}$ \\
\hline H section & \multirow{2}{*}{$0.3 \sim 2.0$} & 0.3 & 4 \\
\hline Box & & $0.7,1.1$ & $45^{\circ}$ \\
\hline Circular & & $0.04,0.06$ & \\
\hline
\end{tabular}

Table 2: Analytical variables related to braces.

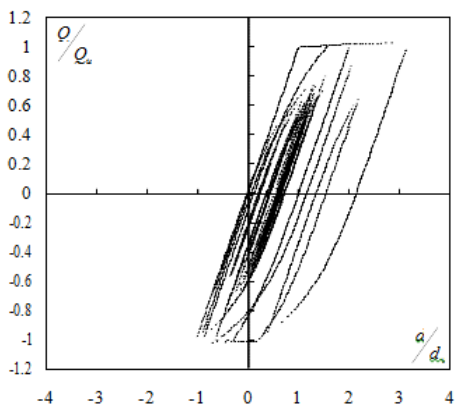

(a) hysteresis loop of moment resisting frames

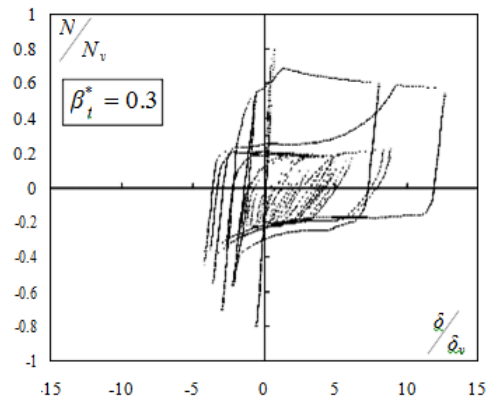

(b) hysteresis loop of a pair of braces

Figure 4: Examples of analytical results.

Non-dimensional slenderness ratio $\lambda^{*}$

$$
\lambda^{*}=\left(1_{\mathrm{b}} / \mathrm{i}\right) \cdot\left(\sqrt{\varepsilon_{\mathrm{y}} / \pi}\right)
$$

Where, $1_{b}$ : effective buckling strength, i: radius strength, $\varepsilon_{\mathrm{y}}$ : yield strain

Non-dimensional width-thickness ratio $\beta^{*}$

(H section) $\quad \beta_{\mathrm{f}}^{*}=\mathrm{b} / \mathrm{t}_{\mathrm{f}} \cdot \sqrt{\varepsilon_{\mathrm{yf}}}$

Where, $b$ : half of flange width, $t_{f}$ : flange thickness, $\varepsilon_{y f}$ : yield strain of flange

$$
\text { (Box) } \beta_{\mathrm{f}}^{*}=\mathrm{B} / \mathrm{t} \cdot \sqrt{\varepsilon_{\mathrm{y}}}
$$

Where, B: width, t: thickness, $\varepsilon_{\mathrm{y}}$ yield strain

(Circular) $\beta^{*}=\mathrm{D} / \mathrm{t} \cdot \varepsilon_{\mathrm{y}}$

Where, D: diameter, $\mathrm{t}$ : thickness, $\varepsilon_{\mathrm{y}}$ : yield strain

\section{Estimation of equivalent strength of a pair of braces}

Equivalent strength Qeq B [8] is defined as follows:

$$
\mathrm{Q}_{\text {eq_B }}=\frac{(\text { Plastic Strain Energy) }}{\text { (Cumulative Plastic Deformation) }}
$$

Herein, Qeq_B is the strength of perfect elasto-plasticity, which is equivalent to the hysteresis loop of a pair of braces with regard to energy absorption. In addition, Qeq_B is converted into normalized axial force per 1 brace by dividing Qeq_B by $2 \mathrm{Ny} \cos \theta$ (Hereinafter, this normalized axial force is written as Neq/Ny). Figures 5 and 6 illustrates the concept of equivalent strength and Figure 6 shows the definition of cumulative deformation in this study [8].

\section{Analytical result and formulization of equivalent strength}

Analytical results are shown in Figures 7 and 8. It is confirmed 
that the equivalent strength becomes small in inversely proportion as the general slenderness ratio increases. In addition, it is confirmed that equivalent strength is mostly not affected by maximum plastic deformation of braces (Here-in-after, maximum plastic deformation is written as $\left.\mu_{\max }\right)$. From the results, equivalent strength is formulized by regression analysis as follows:
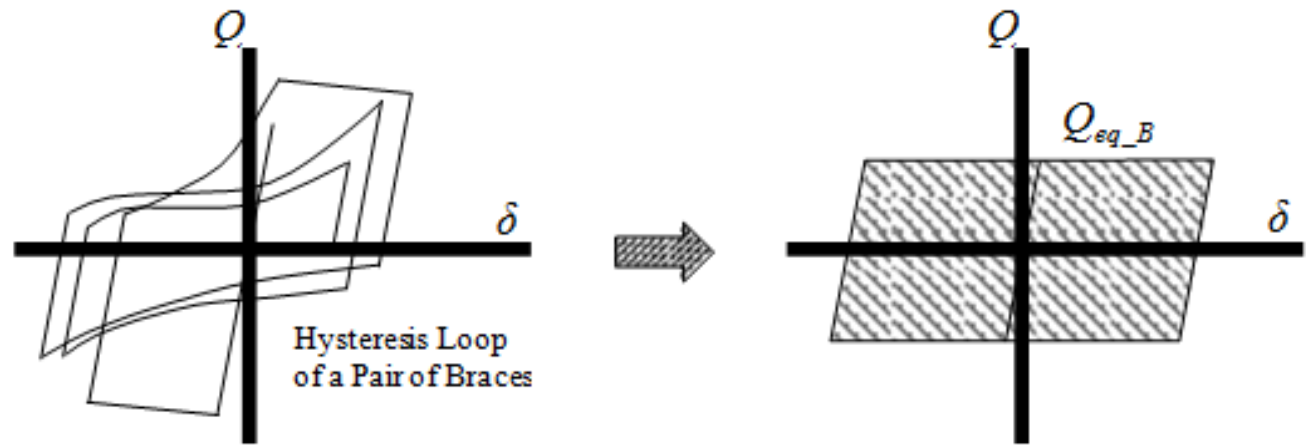

Figure 5: The concept of equivalent strength [5].
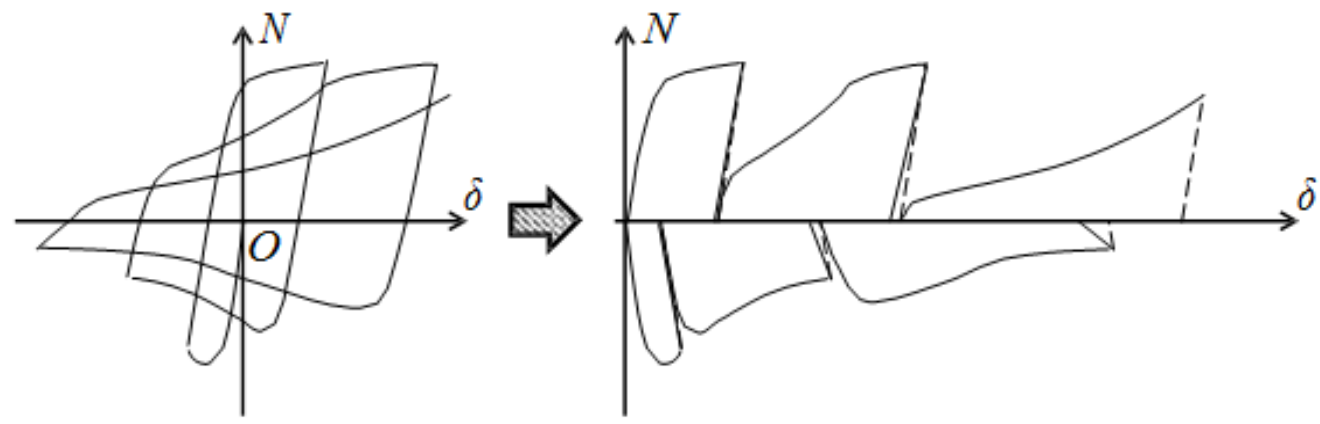

Figure 6: Definition of cumulative deformation [5]

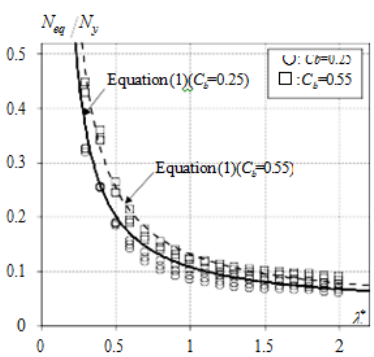

(a) $\mathrm{H}$ section $\left(\beta_{f}^{*}=0.3\right)$

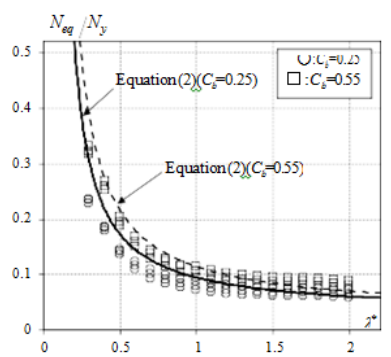

(b) Box-type $\left(\beta^{*}=0.7\right)$

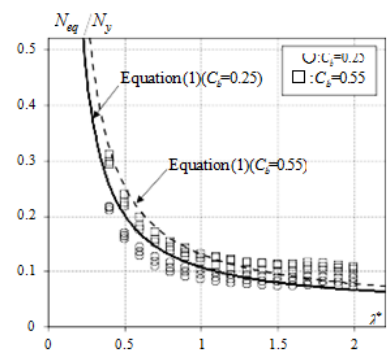

(c) Circular $\left(\beta^{*}=0.04\right)$

Figure 7: Relationship between $N_{e q} / N_{y}$ and $3^{*}$

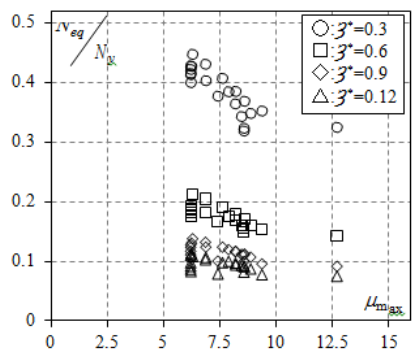

(a) $\mathrm{H}$ section $\left(\beta_{f}^{*}=0.3\right)$

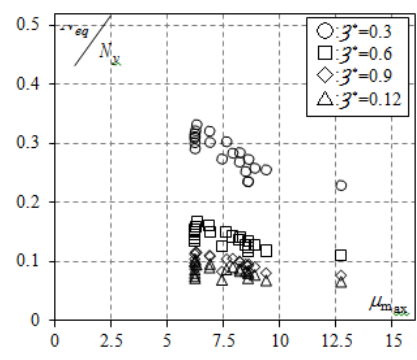

(b) Box-type $\left(\beta^{*}=0.7\right)$

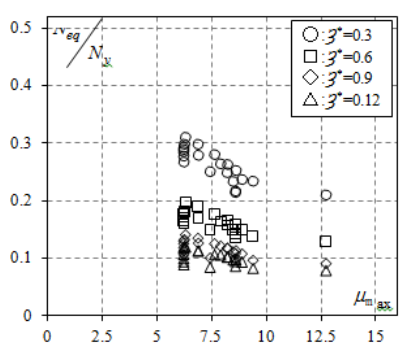

(c) Circular $\left(\beta^{*}=0.04\right)$

Figure 8: Relationship between $N_{e q} / N_{y}$ and ductility factor 
(H-section, Circular)

$$
\frac{\mathrm{N}_{\mathrm{eq}}}{\mathrm{N}_{\mathrm{y}}}=\mathrm{a}_{\mathrm{cb}} \cdot \frac{1.8}{25 \lambda^{*}-2}+0.03
$$

(Box-type)

$$
\frac{\mathrm{N}_{\mathrm{eq}}}{\mathrm{N}_{\mathrm{y}}}=\mathrm{a}_{\mathrm{cb}} \cdot \frac{1.5}{25 \lambda^{*}-2}+0.03
$$

$\mathrm{a}_{\mathrm{cb}}$ : the constant determined by $\mathrm{C}_{\mathrm{b}}$

$$
\begin{aligned}
& \mathrm{C}_{\mathrm{b}}=0.25 \Rightarrow \mathrm{a}_{\mathrm{cb}}=1.0 \\
& \mathrm{C}_{\mathrm{b}}=0.30 \sim 0.35 \Rightarrow \mathrm{a}_{\mathrm{cb}}=1.1 \\
& \mathrm{C}_{\mathrm{b}}=0.40 \sim 0.45 \Rightarrow \mathrm{a}_{\mathrm{cb}}=1.2 \\
& \mathrm{C}_{\mathrm{b}}=0.50 \sim 0.55 \Rightarrow \mathrm{a}_{\mathrm{cb}}=1.3
\end{aligned}
$$

Equations (1) and (2) are illustrated in Figure 7. The evaluation has good agreements with analytical results.

\section{Equivalent Strength of Multi-story Steel Braced Frames}

In $\mathrm{X}$ braced frames, braces are connected to the nodes of columns and beams. Therefore, even though braces of compressive sides buckle, braces of tensile sides keep the strength. In addition, stress of braces is transferred to columns and beams as axial force, therefore, mechanical characteristics of $\mathrm{X}$ braced frames are relatively clear. In contrast, in inverted-V braced frames (Figure 9), after the strength deterioration caused by buckling or fracture is occurred on compression member, an additional shear force is exerted in the middle of the beam. So then, unexpected failure mode will be generated. Moreover, the center of the beam is displaced vertically downward (Figure 9) and displacement history is shifted to the side of compression. From the result, residual buckling deformation of braces occurs, therefore, it is expected that energy absorbing capacity of a pair of braces decreases. In this chapter, seismic response analysis is performed on two types of multi-story braced frames (X-braced, inverted- $\mathrm{V}$ braced) and the energy absorbing efficiency as equivalent strength are evaluated. In addition, the results are compared with the result in Chapter 2.

\section{Outline of analysis}

Analytical frame model: Herein, the low-rise and medium-rise buildings are analyzed, which is designed by reference [11]. And also, the two bracing types of five-story three-bay models (X- bracing, inverted- $\mathrm{V}$ bracing) are modeled. Figure 10 shows two types of model buildings. Here, to guarantee to form the whole story collapse mode, the section size of members is decided (Figure 11). Table 3 shows material properties, and Table 4 shows member lists. Effective length factor of braces is 0.75 or 1.0 to take effect of the members related to braces into account.

Restoring force characteristics model: Restoring force characteristics model of columns and beams is assumed as perfect elastoplasticity model, and break point is full plastic moment without axial force. Restoring force model of braces under axial load is the model of Figure 3. Table 5 shows the list of input motions. Maximum velocity of input motions is normalized to 100 kines.

\section{Analytical result}

Equivalent Strength of a pair of braces is estimated if maximum story drift angle is larger than 1/200 rad. Herein, in according with Japanese seismic design code, ultimate maximum story drift angle is provisioned 1/200 rad. Figure 11 shows comparison between Equivalent Strength and equation (1) in each input motion. From Figure 11, it is confirmed that effective length factor has little influence on equivalent strength of two types of braced frames. In addition, the mean value $(\lambda)$ and the standard deviation $(\sigma)$ show similarity in each type. In regard to X-braced, the upper limit of the standard deviation $1 \sigma$ has good agreements with equation (1) (Figure 12). By contrast, in regard to inverted-v braced, equivalent strength is lower than equation (1). Figure 13 show hysteresis loop of a brace in inverted-V braced frames. It is confirmed that load history is shifted to the side of compression. Therefore, equivalent strength is lower than equation (1).

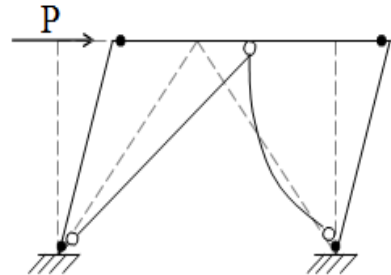

(a) normal mechanism

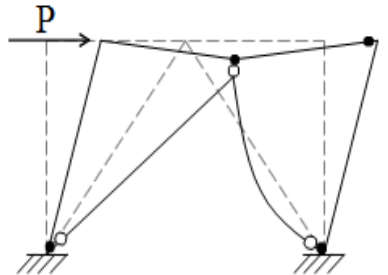

(b) beam-hinging mechanism
Figure 9: Collapse mechanism of inverted-V Braced frames.

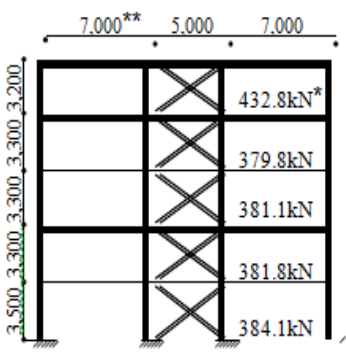

(a) X Braced Frames

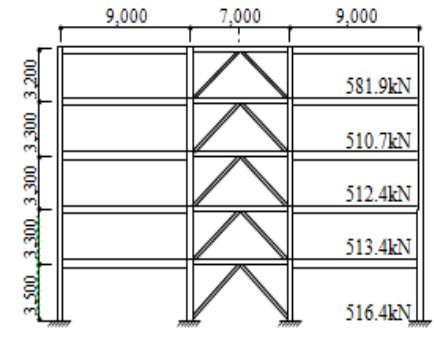

(b) Inverted-V Braced Frames
Figure 10: Model buildings. ( ${ }^{*}$ The figure in Figure.10 (eg. $432.8 \mathrm{kN}$ ) mean the dead load + live load of the stories. ${ }^{* \star}$ The unit of measurement is " $\mathrm{mm}$ ").

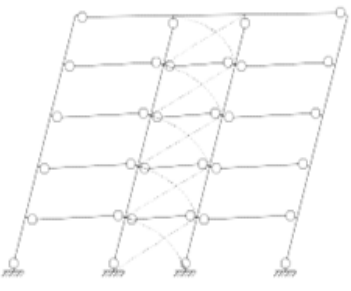

(a) X Braced Frames

\begin{tabular}{|c|c|c|c|}
\hline Members & Steel grades & $\begin{array}{l}\text { Yield stress }(\sigma y) \\
\left(\mathrm{N} / \mathrm{mm}^{2}\right)\end{array}$ & $\begin{array}{l}\text { Young's modulus } \\
\text { (E) }\left(\mathrm{N} / \mathrm{mm}^{2}\right)\end{array}$ \\
\hline Columns & BCR295 & 295 & \multirow{3}{*}{205000} \\
\hline Beams & \multirow{2}{*}{ SN400 } & \multirow{2}{*}{235} & \\
\hline Braces & & & \\
\hline
\end{tabular}

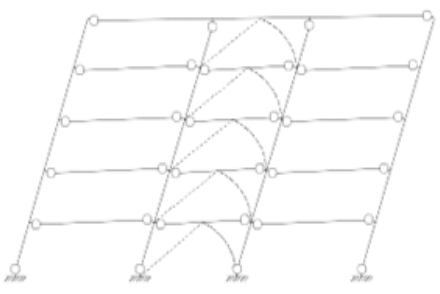

(b) Inverted-V Braced Frames
Figure 11: Collapse mode of examined frames. (*Broken lines show braces; the straight one shows the tensile yielding braces and the curve one shows the buckling braces).

Table 3: Material property. 
Citation: Kinoshita T, Ito T (2016) Study of Equivalent Strength and Effects of the Type of Multi-story Steel Braced Frames. J Civil Environ Eng S3:005. doi:10.4172/2165-784X.S3-005

Page 6 of 8

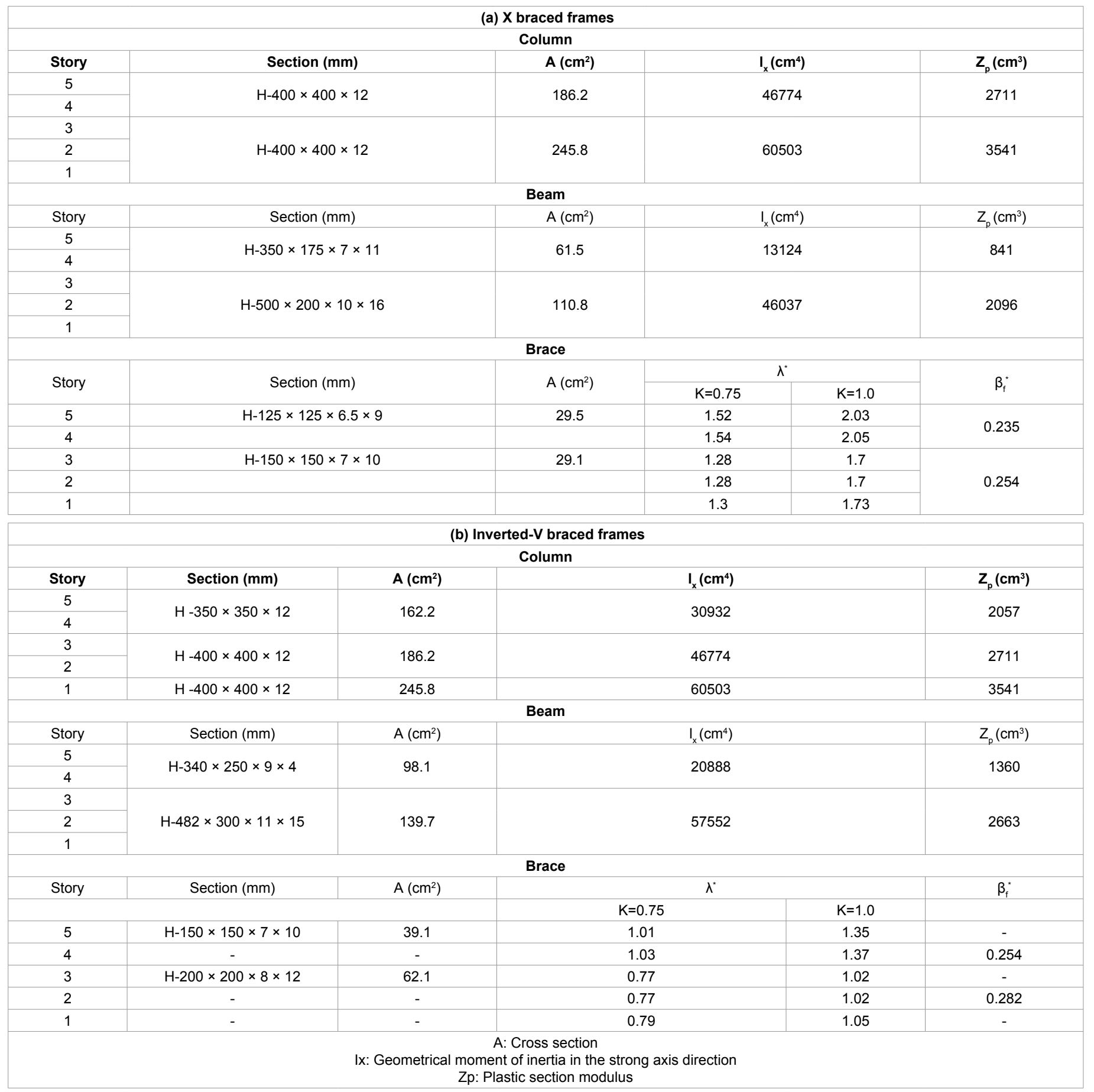

Table 4: Members lists of two types of frames (a) X braced frames and (b) Inverted-V braced frames.

\begin{tabular}{|c|c|c|c|c|c|}
\hline Input motion & Observation date & Magnitude & Maximum acceleration (gal) & Normalized maximum velocity (kine) & Phase characteristics \\
\hline El Centro NS & $1940 / 5 / 19$ & 7 & 900.7 & \multirow{5}{*}{100} & Middle distance \\
\hline Fukiai NS & $1995 / 1 / 17$ & 6.9 & 994.9 & & Short distance \\
\hline Hachinohe EW & $1968 / 5 / 16$ & 7.9 & 468.4 & & Long distance \\
\hline Taft EW & $1995 / 1 / 17$ & 7.4 & 999.0 & & Middle distance \\
\hline BCJ-L2* & \multicolumn{2}{|l|}{-} & 457.9 & & Oceanic \\
\hline
\end{tabular}

Table 5: Input motions. 


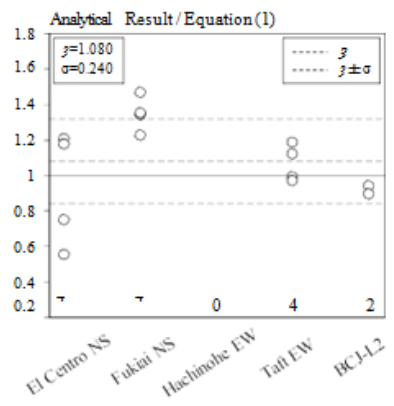

$k=0.75$

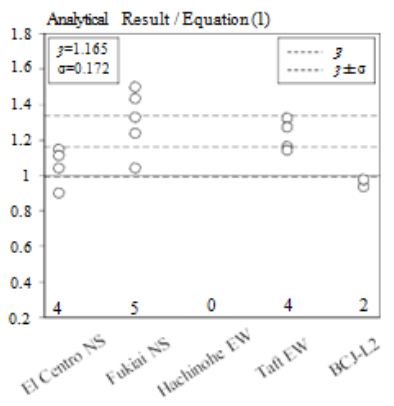

$k=1.0$

(a) X Braced Frames
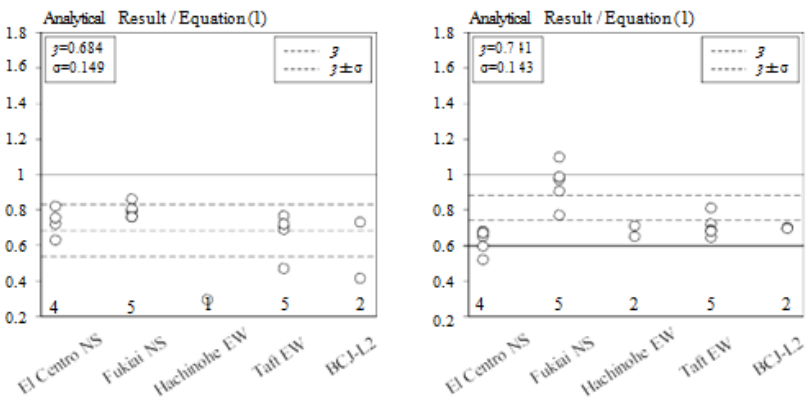

$k=0.75$

$$
k=1.0
$$

(b) Inverted-V Braced Frames

Figure 12: Comparison between equation (1) and equivalent strength in each input motion ( ${ }^{*}$ The figures mean the number of the stories where maximum story drift angle is larger than $1 / 200 \mathrm{rad})$.

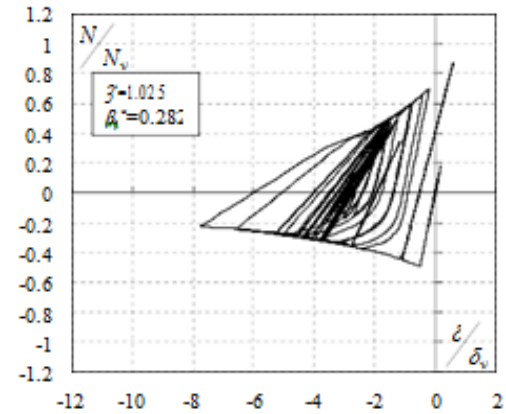

El Centro NS

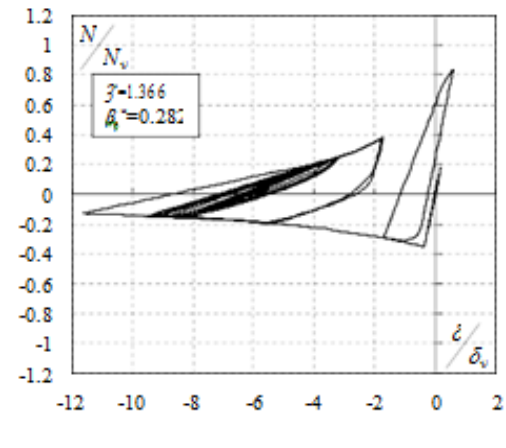

El Centro NS

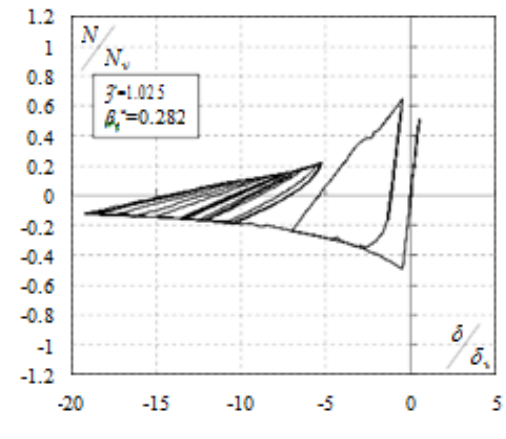

Fukiai NS

(a) $k=0.75$

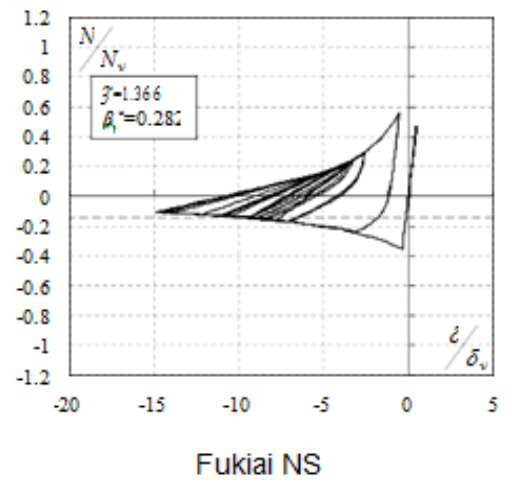

(b) $k=1.0$

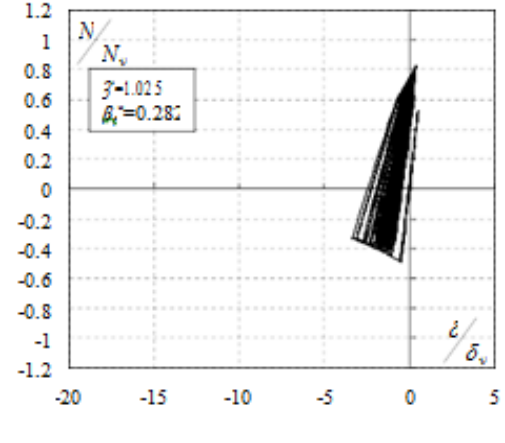

BCJ-L2

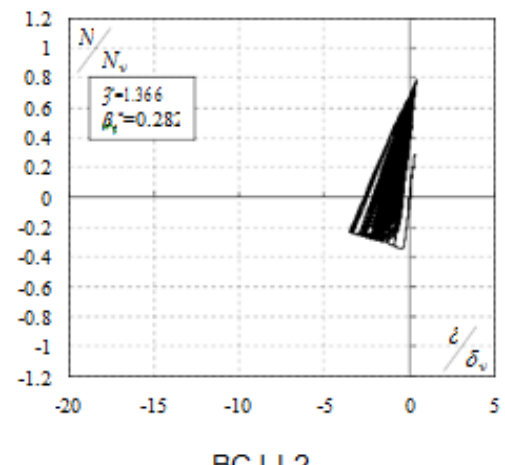

BCJ-L2

Figure 13: Hysteresis loop of braces in inverted-V braced frames.

Besides, it is confirmed that the accuracy of equation (1) is $\pm 20 \%$ or so of the response.

\section{Conclusions}

In this study, the energy absorbing efficiency of steel braced frames is formulized. In addition, seismic response analysis of five-stories threebay steel braced frames was conducted to clarify the applicability to multi-story braced frames. Conclusions as following:

1) Energy absorbing capacity is translated as equivalent strength with normalized slenderness ratio $\lambda^{\star}$ of braces and yield base shear coefficient $\mathrm{Cb}$ of moment resisting frames.

2) From response analysis, equivalent strength has a tendency to vary inversely with $\lambda^{*}$ based on Figure 7 . By contrast, equivalent strength is mostly not affected by maximum plastic deformation of braces based on Figure 8.

3) To clarify the applicability of equation of equivalent strength to multi-story braced frames, seismic response analysis is conducted in two types of braced frames. 
4) The type of bracing has the effect on energy absorbing efficiency of brace. In particular, in case of inverted- $V$ braced frames, energy absorbing efficiency of braces is lower than equation because of the vertical displacement caused by additional axial shear force.

\section{References}

1. Government Publication in Japan (2015) A guideline of building construction technologies.

2. The Building Center of Japan (2006) A guideline of seismic evaluation method based on energy absorbing capacity (2ndedn). IITK-GSDMA Project on Building Codes.

4. Shibata M, Nakamura T, Wakabayashi M (1982) Mathematical expression of hysteric behavior of braces: Part 1, Derivation of Hysteresis Functions. Transactions of the Architectural Institute of Japan 316: 18-24.

3. Kato B, Akiyama H (1977) Restoring force characteristics of steel frames equipped with diagonal bracings. Transactions of the Architect Institute of Japan 260: 99-108.

4. Uritz P, Filippou FC, Mahin SA (2008) Model for cyclic inelastic buckling of steel braces. J Struct Eng.
5. Faggianno B, Fiorino L, Formisano A, Macillo V, Castaldo C, et al. (2014) Assessment of the design provisions for steel concentric $X$ bracing frames with reference to Italian and European codes. The Open Construct and Building Technol J 208-215.

6. Formisano A, Landolfo R, Mazzolani FM (2015) Robustness assessment approaches for steel framed structures under catastrophic events. Computers and Struct 147: 216-228.

7. Matsumoto $\mathrm{Y}$, Ito T, Goto M, Inoue S, Murayama N, et al. (2015) A study on post-buckling behavior and energy dissipation capacity of braced moment frames: Part 1-3. Annual Meeting of Architectural Institute of Japan, Kanto, Japan 1127-1132.

8. Meng L, Ohi K, Takanashi K (1992) A simplified model of steel structural members with strength deterioration used for earthquake response analysis. $J$ Struct of the Architect Institute of Japan 437: 115-124

9. Ito T, Sugiyama S, Inoue S (2015) Restoring force characteristics model considering deterioration behaviour of steel compression members subjected to cyclic loading. J Structure of the Architectural Institute of Japan 710 : 715-725.

10. Consortium for Building Research \& Development (2012-2015) Report of study of box-column steel construction connected with steel braces. 